\title{
Chemiluminescent Determination of the Pesticide Bromoxynil by On-line Photodegradation in a Flow-Injection System
}

\author{
Z. Pawlicová,* J. R. Albert-García,* I. Sahuquillo,** J. V. García Mateo,*** \\ M. Catalá ICardo, $* * *$ and J. Martínez Calatayud $* \dagger$ \\ *Department of Analytical Chemistry, University of Valencia, Valencia, Spain \\ **Department of Chemistry, Biochemistry and Molecular Biology, University Cardenal Herrera-CEU, \\ Moncada, Valencia, Spain \\ ***Department of Chemistry, Polytechnic University of Valencia, Valencia, Spain
}

\begin{abstract}
A new, robust and simple method is proposed for the chemiluminescent determination of the pesticide Bromoxynil. The empirical procedure is performed with the aid of a flow-injection manifold provided with an on-line photo-reactor to obtain chemiluminescent photofragments. After a period of $12 \mathrm{~s}$ of irradiation with an $8 \mathrm{~W}$ low-pressure mercury lamp, a chemiluminescent oxidation was performed with the system potassium permanganate in a polyphosphoric acid medium. The photolysis required a basic medium $\left(\mathrm{KOH} 0.014 \mathrm{~mol} \mathrm{l}^{-1}\right)$ with ethanol $(1 \%)$ as a sensitizer. The method allowed the determination of 134 samples $\mathrm{h}^{-1}$ of Bromoxynil in a wide interval of concentrations, over the range $5 \times 10^{-3}-1 \mathrm{mg} \mathrm{l}^{-1}$; the detection limit was $5 \times 10^{-3} \mathrm{mg} \mathrm{l}^{-1}$. The $\operatorname{RSD}(n=24)$ at $0.25 \mathrm{mg}^{-1}$ of the pesticide level was $2.3 \%$. The method was applied to a water sample and to a formulation.
\end{abstract}

(Received August 6, 2005; Accepted October 28, 2005)

\section{Introduction}

Bromoxynil (3,5-dibromo-4-hydroxybenzonitrile) is a nitrile herbicide ${ }^{1}$ that is used for the post-emergent control of annual broad-leaf weeds, especially in cereal, corn, sorghum, flax, onions, mint and non-cropland. This pesticide acts to inhibit photosynthesis in the target plants. The molecular structure is shown in Fig. 1.

Most of the reported analytical methods for the determination of Bromoxynil are chromatographic, often in tandem with mass spectrometry, with UV detection, or even a combination of both. $^{2}$ There are methods for the determination in atmospheric samples (gas and particles), ${ }^{3}$ crops, ${ }^{4}$ water, ${ }^{5-11}$ from biological origins, ${ }^{12}$ wines with a solid-phase extraction (SPE), ${ }^{13}$ soils, ${ }^{14-16}$ foodstuffs ${ }^{17,18}$ or plants. ${ }^{15}$ Electrochemical detection has been combined with HPLC for the determination of Bromoxynil and Ioxynil in barley. ${ }^{19}$

Two capillary electrophoresis methods ${ }^{20,21}$ provided with solid-phase extraction have been proposed for Bromoxynil determination in the analysis of water samples.

Although separative methods are by far the most commonly used; some attempts for direct determination have been published. Abubaker et $a l . .^{22}$ proposed peroxyoxalate chemiluminescence for the determination of phenol herbicides in soil. An ester is formed by a reaction with anhydride triethylamine and oxalyl chloride in tetrahydrofuran (THF). After eliminating of the supernatant liquid phase under a vacuum, a re-dissolution in THF containing 9,10-diphenylanthracene was implemented and the injection of $\mathrm{H}_{2} \mathrm{O}_{2}$ into a standard quartz spectrophotometer cell yielded light emission, which was measured at two different

$\uparrow$ To whom correspondence should be addressed.

E-mail: jose.martinez@uv.es time intervals of 1 and $3 \mathrm{~s}$. However, the linear range was observed for quite high concentrations, over the range of $10-$ $100 \mathrm{mg} \mathrm{l}^{-1}$.

Phosphorescence has been also used. ${ }^{23}$ The spectra (264 and $420 \mathrm{~nm}$ for excitation and emission, respectively) were recorded in ether-isopentane-ethanol (5:5:2) at $77 \mathrm{~K}$. A linear behavior was found in the range from 0.2 (quantitation limit) to $7.5 \mathrm{mg} \mathrm{l}^{-1}$ of Bromoxynil. Finally, a Photosystem II-based biosensor have been proposed by Koblizek et al. ${ }^{24}$

This present paper contributes to the non-separation methods for the Bromoxynil determination. The selected detector was a luminometer; due to direct chemiluminescence, it provides a strong oxidant and has proved to be a highly sensitive method that is applicable over a wide range of concentrations and with very low detection limits. ${ }^{25,26}$ To obtain the emitter product, online irradiation with UV light was used, as a clean reactive for derivatization. The UV irradiation proved to be an easy and clean way of derivatization to obtain fluorometric ${ }^{27-29}$ or chemiluminescent structures. ${ }^{30-32}$ A discussion of possible photoproducts is included. In order to automate the method, a flow injection analysis (FIA) manifold was developed.

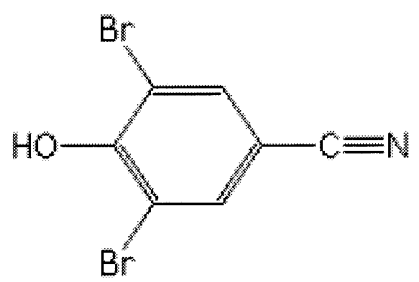

Fig. 1 Molecular structure of the herbicide Bromoxynil. 


\section{Experimental}

\section{Reagents and apparatus}

All of the reagents used were analytically pure, unless stated otherwise, and were prepared in purified water by reverse osmosis and then deionized $(18 \mathrm{M} \Omega \mathrm{cm})$ with a Sybron/Barnstead Nanopure II water-purification system provided with a fiber filter $(0.2 \mu \mathrm{m}$ pore-size $)$.

Bromoxynil was from Dr. Ehrenstorfer; purity 99.8\% according to the label claim. Other used reagents were: $\mathrm{KMnO}_{4}, \mathrm{H}_{2} \mathrm{SO}_{4}, \mathrm{~K}_{3} \mathrm{Fe}(\mathrm{CN})_{6}, \mathrm{NaCl}$, Triton X-100, $\mathrm{Na}_{2} \mathrm{~B}_{4} \mathrm{O}_{7}$. $10 \mathrm{H}_{2} \mathrm{O}, \mathrm{Fe}\left(\mathrm{NO}_{3}\right)_{3} \cdot 9 \mathrm{H}_{2} \mathrm{O}, \mathrm{Cr}\left(\mathrm{NO}_{3}\right)_{3} \cdot 9 \mathrm{H}_{2} \mathrm{O}, \mathrm{N}, \mathrm{N}$-dimethylformamide, 2-propanol, formic acid, $\mathrm{KCl}, \mathrm{N}$-bromosuccinimide, $\mathrm{NaNO}_{3}$ from Panreac; polyphosphoric acid from Riedel-de Haën; $\mathrm{Ce}\left(\mathrm{NH}_{4}\right)_{2}\left(\mathrm{NO}_{3}\right)_{6}, \mathrm{NH}_{4} \mathrm{OH}, \mathrm{NH}_{4} \mathrm{Cl}, \mathrm{Na}_{2} \mathrm{HPO}_{4} \cdot 12 \mathrm{H}_{2} \mathrm{O}, \mathrm{Na}_{2} \mathrm{SO}_{4}$, $\mathrm{CaCl}_{2} \cdot 2 \mathrm{H}_{2} \mathrm{O}, \mathrm{NiCl}_{2}, \mathrm{CuSO}_{4} \cdot 5 \mathrm{H}_{2} \mathrm{O}, \mathrm{NaNO}_{2}, \mathrm{KOH}$ from Probus; ethanol, acetonitrile, $\quad N$-cetyl- $N, N, N$-trimethylammonium bromide from Merck; $\mathrm{NaOH}, \mathrm{HCl}$, acetic acid, $\mathrm{KH}_{2} \mathrm{PO}_{4}$ from $\mathrm{J}$. T. Baker; $\mathrm{FeSO}_{4} \cdot 7 \mathrm{H}_{2} \mathrm{O}$, sodium dodecyl sulfate, hexadecyl pyridinium chloride, $\beta$-cyclodextrine from Fluka; acetone, glycine, polysorbate 80 , quinine sulfate, benzalkonium chloride, $\mathrm{KHCO}_{3}$ from Guinama; $\mathrm{KH}_{2} \mathrm{PO}_{4} \cdot 2 \mathrm{H}_{2} \mathrm{O}$ from UCB; $\mathrm{ZnCl}_{2}$ $\mathrm{CuSO}_{4} \cdot 5 \mathrm{H}_{2} \mathrm{O}$, KI from Scharlau; $\mathrm{MgCl}_{2} \cdot 6 \mathrm{H}_{2} \mathrm{O}, \mathrm{H}_{2} \mathrm{O}_{2}$ from Prolabo. Ioxynil, a pesticide from the Bromoxynil family and assayed as an interferent, was also from Dr. Ehrenstorfer, 99.8\% according to the label claim.

The flow system is illustrated in Fig. 2. It consisted of a photo-reactor made of $173 \mathrm{~cm}$ of a PTFE coil, $0.8 \mathrm{~mm}$ internal diameter (Omnifit), helically coiled around a $8 \mathrm{~W}$ low-pressure mercury lamp (Sylvania) for germicidal use; a Rheodyne Model 5041 injection valve, and a Gilson Minipuls 2 peristaltic pump provided with flexible pump tubing from Omnifit. The measurement of the chemiluminescence emission was achieved by means of a home-made flow-cell that consisted of a flat spiral-coiled quartz tube $(1.0 \mathrm{~mm}$ i.d., $3 \mathrm{~cm}$ total diameter, without gaps between loops). The flow-cell was nested about 2 $\mathrm{mm}$ from the photomultiplier tube window (Model 9125 from Electron Tubes Limited) and backed by a mirror for maximum light collection. A flow-cell and a photomultiplier tube were placed inside a home-made light-tight box. The photomultiplier was operated at $1273 \mathrm{~V}$, supplied by a PHV-40 programmable high-voltage power supply (from Acton Research Corp.).

\section{Procedures}

Preparation of pesticide stock solutions. A stock solution of 20 $\mathrm{mg} \mathrm{l}^{-1}$ Bromoxynil was prepared by exactly weighing and dissolving the pesticide in pure water with the help of an ultrasonic bath. The stock solution was protected against room light with an aluminum foil or a dark plastic foil, and stored in a refrigerator. The kinetic stability of the solution was tested by screening the UV-Vis spectra and checking the chemiluminescent signal every day during one week, and comparing the signal of this solution to that obtained with a freshly prepared solution at the same concentration. Apparently, it seemed to be completely stable at least during the tested interval of 7 days. The working standard solutions were prepared daily by diluting aliquots of the stock solution in deionized water and protected from light.

Optimization procedures. Optimizations of the chemical and flow parameters were performed by a sequential combined methodology. First, the chemical parameters (oxidant system, medium for photodegradation, surfactants, sensitizers, buffers, etc.) were optimized by using an unvaried method. The FIA variables (injection volume, flow rate of the carrier, oxidant and

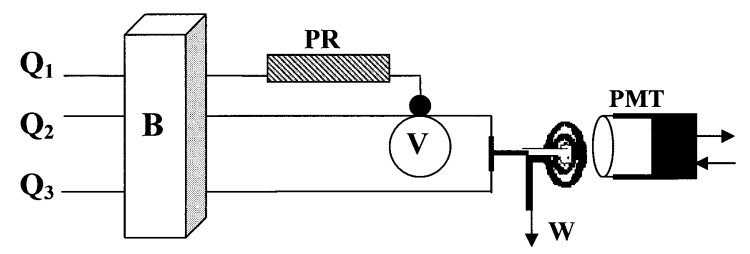

(a)

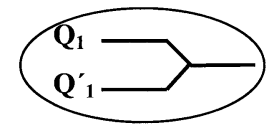

Fig. 2 Optimized flow-assembly. $\mathrm{Q}_{1}$, Bromoxynil in ethanol and $\mathrm{KOH}$ medium; $\mathrm{Q}_{2}$, water as a carrier; $\mathrm{Q}_{3}, \mathrm{KMnO}_{4}$ in a polyphosphoric medium as an oxidative system; $\mathrm{V}$, injection valve; $\mathrm{B}$, peristaltic pump; PR, photoreactor; PMT, photomultiplier tube; W, waste. (a) confluence for mixing solutions (sample and photo-degradation medium solutions) in the assembly for preliminary assays.

sample) were optimized by using a multivariate strategy, the modified simplex method (MSM). ${ }^{33-35}$

Two consecutive simplex procedures were performed, the interval for each variable in the second being restricted to the zone that gave the best results in the first. Then, some of the higher vertices were selected for a new and large comparative ( $n$ $=45$ ) study to choose the output resulting in the best compromise sensitivity (peak height), sample throughput (peakbase width) and reproducibility.

\section{Results and Discussion}

\section{Preliminary assays}

A large preliminary screening experiment was performed, which comprised 160 compounds with different molecular structures. Relevant members of the most important families of pesticides were tested (carbamates, thio-carbamates, organophosphorus, 1,3,5-triazines, urea and sulfonyl urea derivatives, imidazolinones, hydroxybenzonitriles, aryloxyalkoic acids, and so on). ${ }^{36}$ The screening consisted of recording the chemiluminescent outputs of the substances as the result of an oxidative process with permanganate in a sulfuric acid medium, with and without previous irradiation (lamp ON and OFF) of the pesticides with UV light during $2.5 \mathrm{~min}$.

The homogeneous-phase photodegradation of pesticides in different media and combined with chemiluminescence detection of the photo-irradiated analyte was studied. The study of photodegradation was focused on chemical species forming after the UV irradiation of hydroxyl radicals that react with organic pollutants in a non-selective manner, and lead to an efficient photo-catalyst for pesticide degradation. ${ }^{37} \mathrm{NaOH}$, $\mathrm{Fe}$ (II) and $\mathrm{H}_{2} \mathrm{O}_{2}$ employed in the photo-Fenton reaction, ${ }^{38,39}$ and $\mathrm{Fe}(\mathrm{III})$ aqua-complexes described as an efficient photo-catalytic system for the mineralization by sunlight irradiation ${ }^{40}$ were tested.

The light source was placed on-line with the flow manifold, and the sample solution was irradiated through a PTFE tube (136 cm length, $0.8 \mathrm{~mm}$ inner diameter) helically coiled around a $15 \mathrm{~W}$ low-pressure mercury lamp commercially available for germicidal use. The sample solution (pesticide aqueous solution, $50 \mu \mathrm{g} \mathrm{ml}^{-1}$ ) was mixed with the photodegradation medium solution $\left(\mathrm{H}_{2} \mathrm{O}, 1 \times 10^{-3} \mathrm{~mol} \mathrm{l}^{-1} \mathrm{NaOH}, 0.05 \% \mathrm{H}_{2} \mathrm{O}_{2}, 6 \times\right.$ $10^{-5} \mathrm{~mol} \mathrm{1} \mathrm{l}^{-1} \mathrm{Fe}(\mathrm{III})$ or $\left.6 \times 10^{-5} \mathrm{~mol} \mathrm{l^{-1 }} \mathrm{Fe}(\mathrm{II})\right)$. After $150 \mathrm{~s}$ of stopped flow, the photo-degraded pesticide was forced to be 


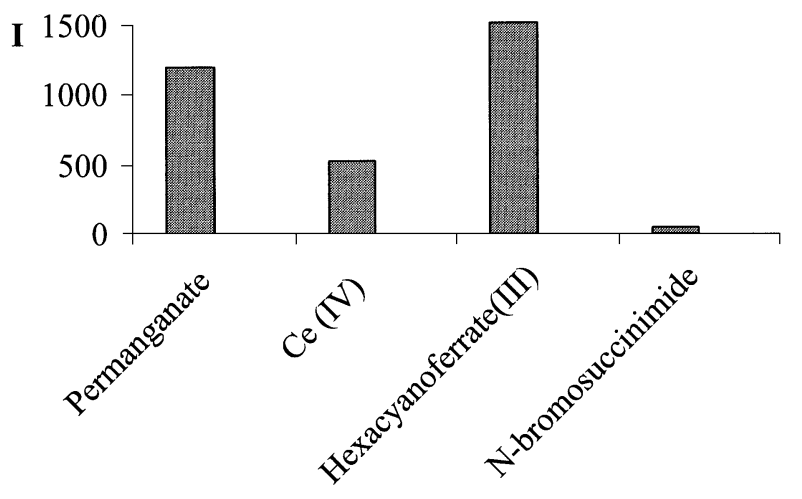

Fig. 3 Influence of the oxidant system in the chemiluminescent behavior of the pesticide Bromoxynil. The signals are corrected by subtracting the blank output.

mixed with the oxidant solution $\left(4 \times 10^{-4} \mathrm{~mol} \mathrm{l}^{-1} \mathrm{KMnO}_{4}\right.$ in 1.5 $\mathrm{mol} \mathrm{l}^{-1} \mathrm{H}_{2} \mathrm{SO}_{4}$ ).

Attending to the observed chemiluminometric response, pesticides could be divided into five groups: (a) compounds that did not present chemiluminescence with the lamp OFF and $\mathrm{ON}$; (b) compounds that decreased the chemiluminescence response with the lamp ON; (c) a group not presenting a relevant increase in the chemiluminescent output with the lamp ON; (d) clearly chemiluminescent-pesticides that increased dramatically the chemiluminescent response with the lamp ON; and, (e) not chemiluminescent pesticides that turned into chemiluminescent ones after irradiation. From an analytical point of view, the most interesting photo-induced chemiluminescence effects were included in groups (d) and (e), and they were suitable for developing new and sensitive chemiluminescent analytical procedures. These two groups comprised $25 \%$ of the pesticides tested. Bromoxynil presented a very weak response with the lamp OFF in all media (three folds the noise of the base line) and increased the chemiluminescent outputs by a factor of 30 in $10^{-3} \mathrm{~mol} \mathrm{l}^{-1} \mathrm{NaOH}$ as the medium of photodegradation. The flow system and solutions adopted for further Bromoxynil determinations are shown in Fig. 2a.

Bromoxynil was selected as the result of the reported wide screening test on pesticides. The flow system illustrated in Fig. 2a was also used for preliminary assays while trying to observe the best medium for the photo-degradation of Bromoxynil.

\section{Selection of the oxidative system}

A suitable oxidant was established by testing some strong oxidant systems, namely: $4 \times 10^{-4} \mathrm{~mol} \mathrm{l}^{-1}$ potassium permanganate or $6 \times 10^{-3} \mathrm{~mol} \mathrm{l}^{-1} \mathrm{Ce}(\mathrm{IV})$ (both of them in 1.5 $\left.\mathrm{mol} \mathrm{l}^{-1} \mathrm{H}_{2} \mathrm{SO}_{4}\right) ; 6 \times 10^{-3} \mathrm{~mol} \mathrm{l}^{-1} \mathrm{Fe}(\mathrm{CN})_{6}{ }^{3-}$ and $4 \times 10^{-2} \mathrm{~mol} \mathrm{l}^{-1}$ $\mathrm{N}$-bromosuccinimide (both in $1.5 \mathrm{~mol} \mathrm{l}^{-1} \mathrm{NaOH}$ ). As illustrated in Fig. 3, the best outputs were obtained with potassium permanganate and hexacyanoferrate(III). An additional experiment was performed to select a suitable system by testing different concentrations of each oxidant. In the considered intervals, 0.002 to $0.030 \mathrm{~mol} \mathrm{l}^{-1}$ for $\mathrm{Fe}(\mathrm{CN})_{6}{ }^{3-}$ and $5 \times 10^{-5}$ to 8 $\times 10^{-4} \mathrm{~mol} \mathrm{l}^{-1}$ for $\mathrm{MnO}_{4}^{-}$, only slight variations were observed for $\mathrm{Fe}(\mathrm{CN})_{6}{ }^{3-}$, whereas a critical dependence with the permanganate concentration was observed. On the other hand, the highest outputs (and smaller blank outputs) were obtained with permanganate; at a concentration of $1.5 \times 10^{-4} \mathrm{~mol} \mathrm{l}^{-1}$ $\mathrm{MnO}_{4}^{-}$it was finally selected for further use.

A medium acid is required for the oxidative action of permanganate; the assayed acids were sulfuric, perchloric and

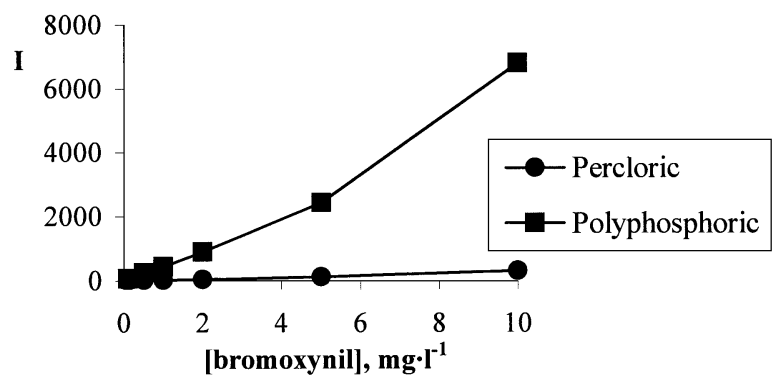

Fig. 4 Influence of $1.5 \mathrm{~mol} \mathrm{l}^{-1}$ perchloric and $0.22 \%$ polyphosphoric acid in the oxidative system for different concentrations of Bromoxynil.

nitric acid in four different concentrations over the range $0.5-$ $2.0 \mathrm{~mol} \mathrm{l}^{-1}$, and polyphosphoric acid in the range from 0.05 to $0.27 \%$ (five different concentrations were tested). While the emission was inhibited when the concentration of nitric acid was increased, no important variations were observed with the different concentrations of sulfuric or perchloric acids; however, the height of the outputs increased with the concentration of polyphosphoric acid up to $0.24 \%$, then the emission started to decrease. Then $1.5 \mathrm{~mol} \mathrm{I}^{-1}$ perchloric and $0.22 \%$ polyphosphoric (which provided the highest outputs) were compared by testing different concentrations of Bromoxynil from 0.1 to $10 \mathrm{mg}^{-1}$ ). Figure 4 shows the results obtained with the best sensitivity for the $0.22 \%$ polyphosphoric acid medium.

Influence of the medium on the photodegradation and/or the chemiluminescence

Modifications on the $\mathrm{pH}$ as well as the presence of some substances, e.g. $\mathrm{Fe}(\mathrm{II})$ or $\mathrm{Fe}(\mathrm{III}), \mathrm{H}_{2} \mathrm{O}_{2}$, organized media or sensitizers, can strongly affect the photodegradation process and the chemiluminescence behavior. The following substances were assayed by merging with the sample solution (shown in Fig. 2a) at the indicated concentration, between branches variation $v s$. reference (aqueous solutions containing $5 \mathrm{mg} \mathrm{l}^{-1}$ of Bromoxynil $\left.{ }^{-}\right)$: $\beta$-cyclodextrine $0.73 \%,(+20 \%)$; benzalkonium chloride $0.54 \%,(-97 \%) ; N$-cetyl- $N, N, N$-trimethylammonium bromide $0.11 \%,(-70 \%)$; hexadecylpyridinium chloride $0.11 \%$, $(-99 \%)$; sodium dodecylsulfate (SDS) $0.68 \%,(+83 \%)$; Triton $\mathrm{X}-1000.064 \%,(+74 \%)$; Tween $800.06 \%,(+47 \%)$; 2-propanol $20 \%,(+294 \%) ;$ acetone $0.5 \%,(-93 \%)$, acetonitrile $20 \%$ $(-97 \%)$; dimethylformamide $5 \%,(+40 \%)$; dioxane $5 \%,(-24 \%)$; ethanol $5 \%,(+465 \%)$; formic acid $0.5 \%,(-13 \%)$; and, quinine sulfate $10^{-4} \mathrm{~mol} \mathrm{l}^{-1},(-13 \%)$. The tensoactive concentrations were prepared with the aim to be at the end of the flow-system (flow-cell of the luminometer) higher than the respective $\mathrm{cmc}$ (critical micellar concentration) value. Substances presenting higher increases, such as ethanol, SDS and Triton X-100, were pre-selected and studied at different concentrations. A study of 2-propanol was refused due to the high blank signal obtained. The intervals assayed (and the optimal concentration) were: ethanol from 0.5 to $5 \%$ (1\%); SDS from 0.68 to $1.00 \%(0.85 \%)$, and Triton X-100 from 0.064 to $0.180 \%(0.1 \%)$.

A more complete study of the photodegradation was performed by also testing other acidic or basic media $\left(\mathrm{H}_{2} \mathrm{SO}_{4}\right.$ and $\mathrm{NaOH}$ at both $1 \times 10^{-3}$ and $0.1 \mathrm{~mol} \mathrm{l}^{-1}$, respectively). An interesting and unique output increase of about $+72 \%$ was observed by employing $1 \times 10^{-3} \mathrm{~mol} \mathrm{l}^{-1} \mathrm{NaOH}$.

The next step was to confirm the suitability of the presence of ethanol plus $\mathrm{NaOH}$. The tested Bromoxynil concentrations were from 0.1 to $10 \mathrm{mg} \mathrm{l}^{-1}$, and as photodegradation media were 


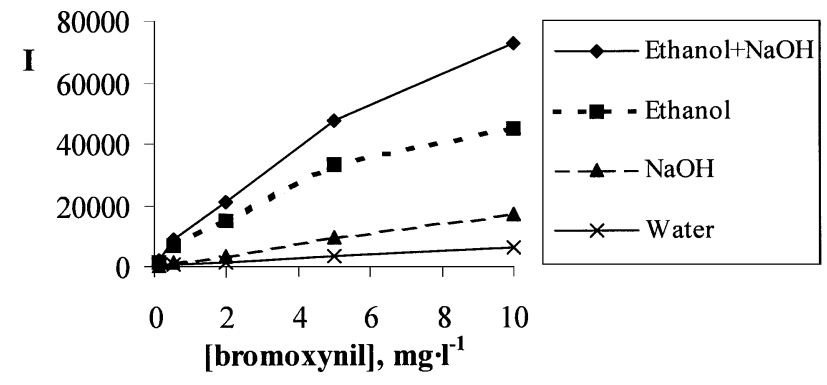

Fig. 5 Influence of ethanol, $\mathrm{NaOH}$, and their combination on the chemiluminescent signal for several Bromoxynil concentrations.

employed $\mathrm{NaOH} 0.001 \mathrm{~mol} \mathrm{l}^{-1}$, ethanol $1 \%$ and $\mathrm{NaOH} 0.001$ mol $~^{-1}$ plus ethanol $1 \%$ (water medium as reference). As shown in Fig. 5, the simultaneous presence of both reagents, ethanol and $\mathrm{NaOH}$ (straight line, up), resulted in higher outputs than both reagents being separated; in fact, the emission intensity was for any tested concentration of the pesticide, over twice the best of these two, the ethanol.

\section{Optimization of flow parameters and photodegradation time}

A multiparametric strategy, a modified simplex method, was selected to optimize the hydrodynamic parameters. The parameters included were the insertion volume, the flow rate of the carrier, the oxidant and the sample $\left(\mathrm{Q}_{1}\right.$ and $\mathrm{Q}^{\prime}{ }_{1}$ were kept at same flow-rate), and, the photo-degradation time. The optimization strategy was performed as reported in the Procedures section. Table 1 gives the intervals assayed for each parameter and the selected optimal conditions.

The irradiation time is a relevant parameter, which is determined by the flow rate of the sample and the photodegradation medium and the length of the reactor tubing. To obtain more profound knowledge about the photo-degradation process, a re-optimization of these flow-rates was performed. The parameter was varied between 1.6 and $2.5 \mathrm{ml} \mathrm{min}^{-1}$. The signal was increased up to an optimal value of $2.2 \mathrm{ml} \mathrm{min}^{-1}$ and decreased for a shorter irradiation time (higher flow-rate). This means that a suitable photo-degradation degree to obtain a chemiluminescent photo-fragment is fast, about $12 \mathrm{~s}$.

Several authors studied the photolysis of Bromoxynil. Miller and coworkers ${ }^{41}$ studied some halobenzonitriles by employing a xenon lamp, XOP7 $(500 \mathrm{~W})$, and noticed fast kinetics of the photoreaction of Bromoxynil. According to these authors, the half-lives in an aquatic environment (for Latitude $50^{\circ}$ and studied using the Program GC-Solar) varied between 0.12 and 4 days in the summer and winter, respectively. However, with UV light this time could be decreased to $11 \mathrm{~min}$, as indicated by Guitonneau and coworkers ${ }^{42}$ and using a low-pressure vapor mercury lamp in which $85 \%$ of the emission is at $254 \mathrm{~nm}$ and a medium $\mathrm{pH} 7$ with a phosphate buffer. Only a small difference in the reactivity was observed when $\mathrm{H}_{2} \mathrm{O}_{2}$ was added to the medium of the reaction, due the short irradiation time for the photolysis of $\mathrm{H}_{2} \mathrm{O}_{2}$. This means that UV light can be a good alternative to remove Bromoxynil from water, although a chemical treatment with ozone can be more effective. The quantum yield (number of molecules undergoing photodegradation transformation per number of photons absorbed by these molecules) can be found in the literature and confirms these observations. ${ }^{42,43}$

Different authors agree with the products of photolysis. ${ }^{42,44,45}$ Hidroxylated compounds (bromine is substituted by an $\mathrm{OH}$ ), as 3,4-dihydroxy-5-bromobenzonitrile and 3,4,5-trihydroxy- benzonitrile, and hydrogenated compounds (substitution of bromine by a $\mathrm{H}$ ) as 3,4-dihydroxybenzonitrile and 4-hydroxybenzonitrile, were observed by GC-MS ${ }^{42}$ after $10 \mathrm{~min}$ of irradiation at $254 \mathrm{~nm}$ (low-pressure vapor mercury lamp) at $\mathrm{pH}$ 7 in a phosphate buffer.

\section{Re-optimization of chemical parameters}

With the new flow conditions, each chemical parameter was re-optimized (univariant method) by testing other values around that previously selected as optimum. The substitution of $\mathrm{NaOH}$ by $\mathrm{KOH}$ resulted in higher outputs. The confluence between the sample and the medium of photodegradation was removed to avoid any unnecessary dilution of the sample. Finally, the selected manifold was as illustrated in Fig. 2 where $\mathrm{Q}_{1}$ is the sample in $0.014 \mathrm{~mol} \mathrm{l}^{-1} \mathrm{KOH}$ and $1 \%$ of ethanol flowing at 4.4

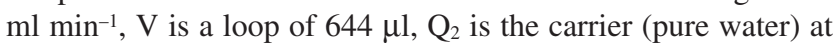
$9.8 \mathrm{ml} \mathrm{min}^{-1}$, and $\mathrm{Q}_{3}$ is $1.4 \times 10^{-4} \mathrm{~mol} \mathrm{l}^{-1} \mathrm{KMnO}_{4}$ in $0.21 \%$ $\mathrm{H}_{4} \mathrm{P}_{2} \mathrm{O}_{7}$ flowing at $2.9 \mathrm{ml} \mathrm{min}{ }^{-1}$.

\section{Analytical figures of merit}

The dynamic range was found to be between $5 \times 10^{-3}$ and $5 \mathrm{mg}$ $1^{-1}$ of Bromoxynil, and fitted with the equation $I=(-10400 \pm$ $1500) C^{2}+(82000 \pm 8000) C+(7000 \pm 4000)$ with a correlation coefficient of 0.9993 , where $I$ is the chemiluminescent emission in counts and $C$ is the pesticide concentration in $\mathrm{mg} \mathrm{l}^{-1}$. The average equation was obtained from five independent calibration graphs, performed with freshly prepared solutions on five different days. The lineal behavior was observed over the range $5 \times 10^{-3}-1 \mathrm{mg} \mathrm{l}^{-1}$, fitting with the equation $I=(88000 \pm$ $7000) C+(5200 \pm 1200)$ with a correlation coefficient of 0.9997 $(n=5)$.

The limit of detection was $5 \mu \mathrm{g}^{-1}$ and which was defined as three-times the blank output height average, and was empirically established by decreasing the concentration of injected Bromoxynil until this relationship was reached.

The repeatability (RSD in \%) for a series of 24 injections of $0.25 \mathrm{mg} \mathrm{l}^{-1}$ of Bromoxynil was $2.3 \%$, and the throughput empirically determined from the same series was $134 \mathrm{~h}^{-1}$.

The chemical robustness of the analytical procedure, or the perseverance of the signal when the chemical or hydrodynamic parameters involving the manifold were altered, was studied in an interval of $\pm 10 \%$ around the optimal conditions. The relative errors were calculated by a comparison with the outputs from the reference (optimal conditions); all of the calculated errors were under $6.0 \%$ for all of the parameters, except for the permanganate and polyphosphoric acid concentrations; to obtain low errors, these parameters required variations into the $5 \%$ interval around he optimal value.

A study of potential interferents (cations and anions present on water samples) was performed by adding different amounts of these substances to a $0.5 \mathrm{mg} \mathrm{l}^{-1}$ Bromoxynil solution and comparing the analytical outputs with the reference (pure Bromoxynil solution); the maximum tested concentrations were $50 \mathrm{mg} \mathrm{l}^{-1}$. The tested ions were: $\mathrm{Ca}^{2+}, \mathrm{Fe}^{3+}, \mathrm{Fe}^{2+}, \mathrm{Mg}^{2+}, \mathrm{Cu}^{2+}$, $\mathrm{Hg}^{2+}, \mathrm{Mn}^{2+}, \mathrm{Cd}^{2+}, \mathrm{Ni}^{2+}, \mathrm{Co}^{2+} \mathrm{NH}_{4}^{+}, \mathrm{Na}^{+}, \mathrm{K}^{+}, \mathrm{SO}_{4}{ }^{2-}, \mathrm{HPO}_{4}^{-}, \mathrm{NO}_{3}^{-}$, $\mathrm{NO}_{2}^{-}, \mathrm{CH}_{3} \mathrm{COO}^{-}$and $\mathrm{Cl}^{-}$. Some of them can be considered as interferents, especially when considering higher concentrations than usual $\left(100 \mathrm{mg} \mathrm{l}^{-1}\right)$. Thus, it was studied how to eliminate the influence of the tested interferents by the previous separation of the pesticide from the matrix. Interference elimination by means of strong cationic and anionic resins of these substances was not adequate. Part of the pesticide was retained by the resins, and checked by recording UV-Vis of the pure pesticide solutions. Different separation experiments were performed in which the retention was tested by recording the 
Table 1 Tested intervals in the two sequentially assayed series (simplex) and selected flow conditions

\begin{tabular}{lccc}
\hline \multicolumn{1}{c}{ Parameter } & $\begin{array}{c}\text { Studied range } \\
1^{\circ} \text { simplex }\end{array}$ & $\begin{array}{c}\text { Studied range } \\
2^{\circ} \text { simplexes }\end{array}$ & Selected value \\
\hline Flow-rate $\mathrm{Q}_{1}$ and $\mathrm{Q}_{1^{\prime}}$ & $0.9-1.7 \mathrm{ml} \mathrm{min}^{-1}$ & $1.8-2.6 \mathrm{ml} \mathrm{min}^{-1}$ & $2.5 \mathrm{ml} \mathrm{min}^{-1}$ \\
Flow-rate $\mathrm{Q}_{2}$ & $4.0-8.0 \mathrm{ml} \mathrm{min}^{-1}$ & $5.6-11.0 \mathrm{ml} \mathrm{min}^{-1}$ & $9.8 \mathrm{ml} \mathrm{min}^{-1}$ \\
Flow-rate $\mathrm{Q}_{3}$ & $1.4-2.8 \mathrm{ml} \mathrm{min}^{-1}$ & $1.8-3.2 \mathrm{ml} \mathrm{min}^{-1}$ & $2.9 \mathrm{ml} \mathrm{min}^{-1}$ \\
Inserted volume & $100-763 \mu \mathrm{l}$ & $407-661 \mu \mathrm{l}$ & $644 \mu \mathrm{l}$ \\
\hline
\end{tabular}

UV-Vis spectra of the pesticide before and after passing them through the adsorbent column. The procedure that gave suitable results consisted of forcing a solution containing $0.25 \mathrm{mg} \mathrm{l}^{-1}$ of the pesticide and $500 \mathrm{mg} \mathrm{l}^{-1}$ of all the above-mentioned reported ions through a column SAX (Bond Elut SAX, Varian). The column was then treated with $10 \mathrm{ml}$ of deionized water, and elution was performed with $0.1 \mathrm{~mol} \mathrm{l}^{-1}$ of $\mathrm{HCl}$. To the obtained solution was added $1 \mathrm{ml}$ of $0.1 \mathrm{~mol} \mathrm{l}^{-1} \mathrm{KOH}$. Finally, after adding $0.25 \mathrm{ml}$ of ethanol, the solution was levelled to $25 \mathrm{ml}$ with $0.015 \mathrm{~mol} \mathrm{l}^{-1}$ of $\mathrm{KOH}$. The relative error by comparing with the pesticide solution containing no interferents was $-1.7 \%$. Ioxynil, a pesticide of the Bromoxynil family, was also assayed as a potential interferent; a solution containing $0.25 \mathrm{mg}$ $1^{-1}$ of this pesticide provided an error of $3.5 \% \mathrm{vs}$. the reference solution.

The method was applied to the determination of Bromoxynil in two different type of samples. A formulation-type WG (Water Dispersable Granulate) was prepared in the laboratory (no commercially formulations were available from local manufacturers) with a composition of $20 \%$ Bromoxynil, 20\% magnesium stearate, $30 \%$ talc and $30 \%$ starch. Added inert compounds were EPA (Environmental Protection Agency ${ }^{46}$ ) authorized. After dilution to obtain a concentration of $0.5 \mathrm{mg} \mathrm{l}^{-1}$ Bromoxynil, the average of three determinations resulted in a $(110 \pm 6) \%$ recovery. The other sample was tap water, which was spiked with $0.250 \mathrm{mg} \mathrm{l}^{-1}$ of the herbicide; the obtained recovery was $104 \%$.

\section{Conclusions}

A new continuous-flow procedure for the chemiluminescent determination of the herbicide Bromoxynil is presented.

The method includes the on-line photo-degradation of Bromoxynil and oxidative reaction with permanganate in a polyphosphoric acid medium for light emission. The presence of $\mathrm{KOH}$ and ethanol increased the sensitivity of the process.

A wide linear interval was observed $\left(5 \times 10^{-3}-1 \mathrm{mg} \mathrm{l}^{-1}\right)$ with a very low limit of detection compared with another luminescent method described in the literature. ${ }^{22}$ The automated method allowed the determination of 134 samples in $1 \mathrm{~h}$, and resulted in competitive chemical robustness $v s$. variations of about $5-10 \%$ variations in the chemical and flow parameters.

Solid-liquid separation (the column can be easily inserted online into the flow system) allows the procedure to be applied to water samples containing the majority of usually present interferents. It can also be applied to commercially available formulations without requiring sample pretreatments. The interferent of an herbicide of the same chemical family, the Ioxynil, was not relevant.

This research was supported by Ministerio Educación y Ciencia (Spanish Government), Project BQU2002-04248-C02-01.

\section{References}

1. http://www.hclrss.demon.co.uk/bromoxynil.html

2. R. Jeannot, H. Sabik, E. Sauvard, and E. Genin, J. Chromatogr., A, 2000, 879, 51.

3. S. Morville, A. Scheyer, P. Mirabel, and M. Millet, J. Environ. Monit., 2004, 6, 963.

4. J. Klein and L. Alder, J. AOAC Int., 2003, 86, 1015.

5. T. W. Moy, and W. C. Brumley, J. Chromatogr. Sci., 2003 , $41,343$.

6. R. Bossi, K. V. Vejrup, B. B. Mogensen, and W. A. H. Asman, J. Chromatogr., A, 2002, 957, 27.

7. E. Dijkman, D. Mooibroek, R. Hoogerbrugge, E. Hogendoorn, J. V. Sancho, O. Pozo, and F. Hernandez, J. Chromatogr., A, 2001, 926, 113.

8. R. Curini, A. Gentili, S. Marchese, D. Perret, L. Arone, and A. Monteleone, Chromatographia, 2001, 53, 244.

9. G. Brausen and R. Reupert, LaborPraxis, 2000, 24, 70.

10. K. Vandecasteele, I. Gaus, W. Debreuck, and K. Walraevens, Anal. Chem., 2000, 72, 3093.

11. J. Lipinski, Fresenius' J. Anal. Chem., 2000, 367, 445.

12. H. Brzezinka and N. Bertram, J. Chromatogr. Sci., 2002, 40,609 .

13. J. W. Wong, M. G. Webster, C. A. Halverson, M. J. Hengel, K. K. Ngim, and S. E. Ebeler, J. Agric. Food Chem., 2003, 51, 1148.

14. E. A. Hogendoorn, R. Huls, E. Dijkman, and R. Hoogerbrugge, J. Chromatogr., A, 2001, 938, 23.

15. C. Sánchez-Brunete, A. I. García-Valcarcel, and J. L. Tadeo, Chromatographia, 1994, 38, 624.

16. G. W. Bruns, S. Nelson, and D. G. Erickson, J. Assoc. Anal. Chem., 1991, 74, 550.

17. H. J. Stan, J. Chromatogr., A, 2000, 892, 347.

18. A. Cessna, J. Agric. Food Chem., 1990, 38, 1844.

19. W. Buchberger, H. Malissa, and K. Winsauer, Mikrochim. Acta, 1984, I, 53.

20. Z. Aturki, C. Desiderio, and C. M. Polcaro, Chromatographia, 2001, 54, 489.

21. X. L. Liu, J. F. Wang, J. D. Wang, Z. H. Shang, and H. Frank, Sepu, 2001, 19, 173.

22. M. A. Abubaker and R. Von-Wandruszka, Anal. Lett., 1991, 24, 93

23. N. L. Trautwein and J. C. Guyon, Anal. Lett., 1983, 16, 969.

24. M. Koblizek, J. Masojidek, J. Komenda, T. Kucera, R. Pilloton, A. K. Mattoo, and M. T. Giardi, Biotechnol. Bioeng., 1998, 60, 664.

25. E. Polo Martí, M. Catalá Icardo, L. Lahuerta Zamora, G. M. Antón Fos, and J. Martínez Calatayud, Anal. Chim. Acta, 2004, 527, 177.

26. N. W. Barnett, B. J. Hindson, and S. W. Lewis, Analyst, 2000, 125, 91.

27. T. Pérez-Ruiz, C. Martínez-Lozano, V. Tomas, and J. 
Martin, Anal. Chim. Acta, 2004, 514, 259.

28. E. M. Almansa-López, A. M. García-Campaña, J. J. Aaron, and L. Cuadros-Rodríguez, Talanta, 2003, 60, 355.

29. J. J. Aaron and A. Coly, Analusis, 2000, 28, 699.

30. A. Chivulescu, M. Catalá Icardo, J. V. García Mateo, and J. Martínez Calatayud, Anal. Chim. Acta, 2004, 519, 113.

31. M. Palomeque, J. A. García Bautista, M. Catalá Icardo, J. V. García Mateo, and J. Martínez Calatayud, Anal. Chim. Acta, 2004, 512, 149.

32. M. Mervartová, J. Martínez Calatayud, and M. Catalá Icardo, Anal. Lett., 2005, 38, 179.

33. L. A. Yabro and S. N. Derming, Anal. Chim. Acta, 1974, 73,1043 .

34. S. L. Morgan and S. N. Derming, Anal. Chem., 1974, 46, 1170 .

35. J. A. Nelder and R. Mead, Comput., 1965, 7, 308.

36. J. V. García Mateo, I. Sahuquillo Ricart, and M. Escartí Carrasco, XX IUPAC Symposium on Photochemistry, 2004, Granada, Spain.

37. "Environmental Chemistry", 2nd ed., 1995, W. H. Freeman and Company, New York, $509-510$.

38. R. Bauer and H. Fallmann, Res. Chem. Intermed., 1997, 23, 341

39. P. L. Huston and J. J. Pignatello, Water Res., 1999, 33, 1238.

40. C. Catastini, G. Mailhot, S. Malato, and M. Sarakha, Paper presented at the IHP-Users Workshop 2002.

41. M. Miller, W. U. Palm, and C. Zetzsch, Ecotoxicol. Environ. Saf., 1998, 41, 44.

42. S. Guitonneau, S. Momege, A. Schafmeier, P. O. Viac, and P. Meallier, Rev. Sci. Educ., 1995, 8, 201.

43. J. Kochany, G. G. Choudhry, and G. R. B. Webster, in "Chemistry for the Protection of the Environment", ed. Pawlowski et al., 1990, Plenum, New York, 259 - 276.

44. F. Machado, L. Collin, and P. Boule, Pestic. Sci., 1995, 45, 107.

45. P. Boule, C. Guyon, and J. Lemaire, Chemosphere, 1982, 11, 1179 .

46. http://www.epa.gov/opprd001/inerts/lists.html 